\title{
Yaw Motion Stability of an Indonesian Ro-Ro Ferry in Adverse Weather Conditions
}

\author{
Daeng Paroka ${ }^{1^{*}}$ \\ ${ }^{1}$ Department of Ocean Engineering, Faculty of Engineering, Hasanuddin University, Gowa Campus, Jl. Poros \\ Malino Km. 6, South Sulawesi 92171, Indonesia
}

\begin{abstract}
The yaw motion stability and course-keeping ability of ships are important factors with regard to collision danger, particularly for ships operating in narrow channels, crowded routes, or port areas. Yaw motion may become unstable due to external forces, such as wind. To investigate yaw stability and course-keeping ability, this study developed a nonlinear dynamic system of a three-degree-of-freedom mathematical model to determine steady state equilibrium. Yaw motion behavior was then analyzed using the eigenvalue characteristic of the obtained equilibrium points. The numerical results for an Indonesian ro-ro ferry showed that the rudder angle required to maintain the ship's course tended to increase as wind velocity increased. In beam wind, the necessary rudder angle was larger than the maximum possible rudder angle when the wind velocity was $24 \mathrm{~m} / \mathrm{s}$ or more. The ship could be controlled by the rudder during operation, but its yaw motion tended to be unstable in following wind. The stable oscillation of yaw motion occurs when the wind velocity is higher than $11 \mathrm{~m} / \mathrm{s}$, and the range of heading and rudder angles increases as wind velocity increases.
\end{abstract}

Keywords: Limit cycles; Maneuvering; Ro-ro ferry;Yaw motion

\section{Introduction}

The maneuvering performance of a ship is indicated by its turning ability, zig-zag maneuverability, course-keeping ability, and stopping ability, which are considered as maneuvering criteria by the International Maritime Organization (IMO; 2002). During the initial design of a ship, its maneuvering performance is evaluated through numerical simulation or free-running model experiments. After a ship is launched, tests are conducted in a sea trial to guarantee the maneuverability of the vessel. External disturbances, such as wind and waves, are not considered in the aforementioned criteria, although some studies have shown that these factors have significant effects on the maneuvering performance of a ship (Paroka et al., 2017; Shigunov, 2018). The rudder angle required to maintain a ship's course increases if wind velocity and wave height increase. In severe weather, the rudder may not control the ship's direction because the required rudder angle is larger than the maximum possible rudder angle (Fujiwara et al., 2006).

When a ship operates in a narrow channel, river, or port area, yaw motion stability becomes highly important for the avoidance of collisions during operation. Several studies 
regarding yaw stability have been conducted. Spyrou (1995) investigated the yaw motion of four different ship types under wind action and found that yaw motion tends to be unstable in following wind and stable in headwind. It was also found that a ship's direction is significantly influenced by yaw motion stability. In addition, limit cycles of yaw oscillation were identified within a certain range of heading and rudder angles for specified wind velocities and directions. A ship's heading angle oscillates at constant amplitude under a constant rudder angle. Detailed information regarding the effect of wind on the behavior of yaw motion is necessary to safely and effectively control a ship during operation. For this purpose, Spyrou et al. $(2005,2007)$ investigated this area in relation to rudder angle. In these studies, Spyrou et al. $(2005,2007)$ found that limit cycles of oscillation occur at small rudder angles with low wind velocities, but they did not provide any explanations of yaw motion stability at higher wind velocities. Further investigation of yaw behavior under wind action was undertaken by Yasukawa et al. (2012), who specifically studied the effects of wind velocity and wind direction on yaw, including the oscillation of yaw motion. These studies used a three-degree-of-freedom (3-DOF) mathematical model of ship maneuverability under the assumption that the ship's forward speed does not significantly change due to wind and that the drift motion is small. This method is easy to use because the maneuvering equations can be analytically solved under these assumptions. However, ships with small draught may experience a large amount of drift motion in headwinds, meaning that their forward speed cannot be assumed to be the same as their surge velocity due to significant sway. In addition, the added resistance of the wind may significantly decrease forward speed, especially for small ships with large windage areas.

A ship master should have accurate information regarding alterations in yaw stability according to wind velocity and wind direction relative to their ship. A ship can be controlled by making changes to the rudder angle and propulsion in order to avoid dangerous situations, such as potential collisions (Spyrou et al., 2005). Course-keeping ability failures due to yaw instability depend on wind velocity and direction as well as the geometric characteristics of the windage area (Liu et al., 2018). In high wind velocities, the heading angle cannot be controlled by the rudder, and thus the ship cannot maintain her trajectory (Aung \& Umeda, 2018). Indonesian ro-ro ferries have small draught and large windage areas relative to their overall dimensions (Asri et al., 2014), and wind-induced drift could significantly affect their maneuverability with regard to yaw stability and course-keeping ability. Muhammad et al. (2015) used azimuthing podded propulsion to improve the maneuverability of an Indonesian ro-ro ferry, but this was only advantageous for turning maneuvers. Therefore, the effect of wind on yaw motion and the related coursekeeping ability is an important factor in the minimization of collision risk during the operation of ro-ro ferries. A numerical simulation incorporating variations in wind velocity and direction is a useful method of verifying the yaw characteristics of a ship in different wind conditions.

This paper discusses the yaw motion characteristics and course-keeping ability of an Indonesian ro-ro ferry under the action of steady wind. In this study, the rudder angles required to maintain the heading angle and the yaw stability were measured at specific wind velocities and directions. This information is important for the avoidance of collision dangers. Therefore, the yaw characteristics obtained in this study can be used as guidance for ship masters to safely operate their ships. This information should also be considered in the development of traffic separation schemes to prevent accidents, as proposed by Sunaryo et al. (2015). Finally, these results may be used for the future design of Indonesian ro-ro ferries. 


\section{Methods}

\subsection{Mathematical Model}

Numerical simulations of ship maneuvering usually use 3-DOF mathematical models consisting of surge, sway, and yaw motions. A 4-DOF mathematical model including a roll equation has also been used to investigate the effect of maneuvering on ship stability (Spyrou et al., 2007). Both 3-DOF and 4-DOF mathematical models of ship maneuvering under the action of wind are developed based on the local and global coordinate system shown in Figure 1. The local coordinates originate in the midship section with the axis indicated by $x$ and the ordinate indicated by $y$. The surge velocity, sway velocity, and yaw rate are indicated by $u, v$, and $r$, respectively. The drift angle is indicated by $\beta$, and the ship velocity $(U)$ is resultant of the surge and sway velocities. The axis of the global coordinate is designated as $x_{0}$, and its ordinate is indicated by $y_{0}$. The heading angle $(\psi)$ and the wind direction $\left(\psi_{A}\right)$ are determined from the global coordinate system. Here, $\delta$ is the rudder angle. This system demonstrates that the wind direction relative to the ship depends on both the heading angle and the wind direction.

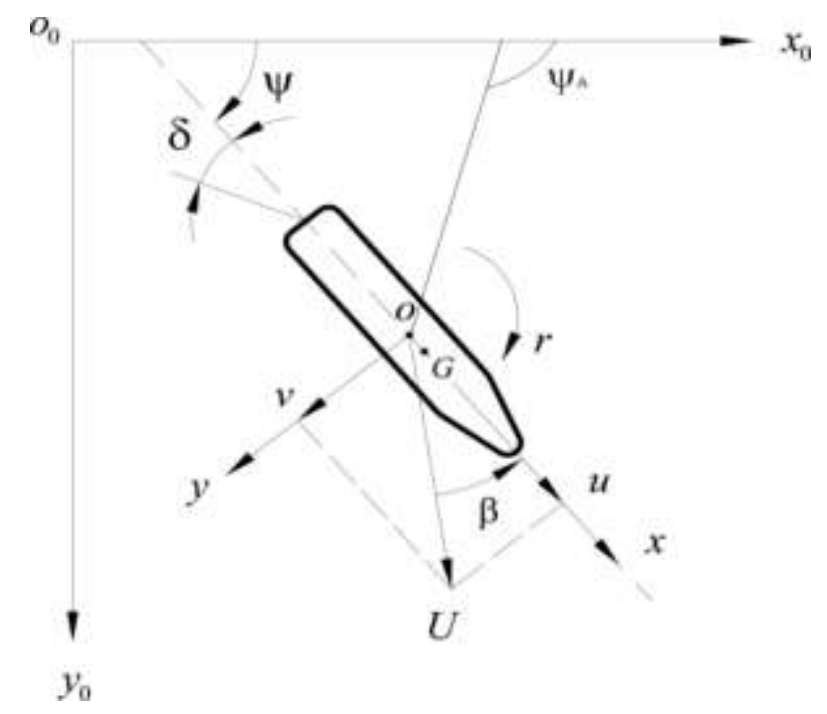

Figure 1 Coordinate system

A well-established mathematical model for the purpose of numerical simulations is the mathematical modelling group (MMG), in which the 3-DOF approach can be expressed as follows (Fujiwara et al., 2006):

$$
\begin{gathered}
m(\dot{u}-v r)=X_{H}+X_{P}+X_{R}+X_{A} \\
m(\dot{v}-u r)=Y_{H}+Y_{R}+Y_{A} \\
I_{z Z} \dot{r}=N_{H}+N_{R}+N_{A}-x_{G}\left(Y_{H}+Y_{R}+Y_{A}\right)
\end{gathered}
$$

here, $m$ is the ship mass and $I_{z Z}$ is its inertia in yaw motion. The acceleration of surge, sway, and yaw are $\dot{u}, \dot{v}$, and $\dot{r}$, respectively. Surge, sway, and yaw rate are designated by $u, v$, and $r$, respectively. The longitudinal position of the ship's center of gravity in the local coordinate system is designated by $x_{G}$. The subscripts $H, P, R$, and $A$ indicate the hydrodynamic forces and moments induced by the ship's hull, propeller thrust, rudder forces, and moment, respectively, as well as those forces and moments induced by the wind.

In Equation 1, the hydrodynamic forces and moments of the ship hull are estimated using the empirical formulae proposed by Yoshimura and Matsumoto (2012), the 
propeller thrust is estimated using the regression equation obtained from open water test data for B-series propeller (Carlton, 2007) the rudder forces and moment are estimated using the formula proposed by Kijima et al. (1990) and those forces induced by the wind are estimated using Fujiwara's formula (Fujiwara et al., 2006). The formulae used to calculate the hull, propeller, rudder, and wind-induced forces and moments have been reported by Paroka et al. (2015).

Equation 1 can be written as a first-order differential equation of a dynamical system with the rudder angle as a control variable, as follows:

$$
\dot{z}=F(z(\delta), \delta)
$$

The state vector, $z$, consists of the surge and sway velocities, the yaw rate, and the heading angle; thus, $z=(u, v, r, \psi)^{T}$. The steady state equilibrium of the dynamical system of Equation 2 was determined to investigate yaw motion characteristics under steady wind. Under equilibrium conditions, the dynamical system in Equation 2 can be written as follows:

$$
F(z(\delta), \delta)=0
$$

Then, the Newton-Raphson method is used to solve Equation 3 for a specified rudder angle to obtain the surge and sway velocities as well the heading angle. The yaw rate vanishes in the equilibrium condition. Here, the rudder angle ranges between $-35^{\circ} 35$ and $+35^{\circ}$, the maximum rudder angle of the ship.

Yaw stability is subsequently analyzed by calculating the eigenvalues of the system in the equilibrium condition. By applying perturbation $(\xi)$ to the equilibrium point and expanding the right-hand side of Equation 2 using Taylor expansion, the equation for steady state equilibrium can be written as follows:

$$
\dot{z}_{E}+\dot{\xi}=F\left(z_{E}\right)+F_{z}\left(z_{E}\right) \xi+\frac{1}{2} F_{z z}\left(z_{E}\right) \xi^{2}+\frac{1}{6} F_{z z z}\left(z_{E}\right) \xi^{3}+\cdots
$$

The time derivative of the vector state $\left(\dot{z}_{E}\right)$ and the resultant forces and moments $\left(F\left(z_{E}\right)\right)$ in equilibrium are equivalent to zero, as defined in Equation 3. If the applied perturbation is small enough, the high-order terms of Equation 4 can be neglected to find a linear first-order differential equation as follows:

$$
\dot{\xi}=F_{z}\left(z_{E}\right) \xi
$$

Here, $F_{z}\left(z_{E}\right)$ is the partial derivative of the forces and moments to the variable vector state in the equilibrium point $z_{E}$. This equation shows that the stability of steady state equilibrium depends on the eigenvalues of the matrix $F_{z}\left(z_{E}\right)$. If the real parts of all the eigenvalues are negative, the equilibrium point is stable. This means that the ship course (heading angle) can be maintained with a constant rudder angle. However, if one eigenvalue has a positive real part, the equilibrium point is unstable. In this case, the heading angle increases with time for a constant rudder angle if a small disturbance is applied to the equilibrium condition toward a stable equilibrium point. The transition between stable and unstable yaw motion can be observed in a change from negative to positive real eigenvalue parts. Additionally, yaw oscillation occurs if the imaginer part of at least one eigenvalue is not zero. This oscillation can be a stable or unstable limit cycle depending on the characteristics of the real parts of the eigenvalues (Somieski, 2001). If the real parts of the eigenvalues change from positive to negative, the limit cycles are stable in the region of variable state smaller than this transition point. The ship's heading 
angle and yaw rate oscillate at a constant amplitude under a constant rudder angle. The limit cycles are unstable in the region of variable state larger than the transition point if the real part of the eigenvalue changes from negative to positive. The oscillation amplitude of the heading angle and yaw rate may increase or decrease in response to a small disturbance when the rudder angle is kept constant. As a result, the heading angle moves to a stable equilibrium point. Stable oscillation can also occur in a variable state region if the first derivative of the real part of the eigenvalue to the variable state is negative. In contrast, oscillation is unstable if this derivative is positive.

To verify the yaw motion characteristics, a simulation of ship maneuvering was conducted by solving Equation 1 through numerical integration using Runga-Kutta method with the obtained equilibrium point as the initial condition. Alteration of the heading angle from unstable to stable conditions and yaw oscillation in the region of stable and unstable limit cycles can be obtained from the results of this numerical simulation.

\subsection{Ship Data}

The mathematical models outlined here in were applied to investigate the yaw characteristics of an Indonesian ro-ro ferry with the principle dimensions shown in Table 1 and the propeller and rudder characteristics shown in Table 2.

Table 1 Principle dimension of the ro-ro ferry

\begin{tabular}{lr}
\hline \multicolumn{1}{c}{ Parameter } & \multicolumn{1}{c}{ Value } \\
\hline Length, overall $\left(\mathrm{L}_{\mathrm{OA}}\right)$ & $56.70 \mathrm{~m}$ \\
Length, between perpendicular $\left(\mathrm{L}_{\mathrm{BP}}\right)$ & $50.50 \mathrm{~m}$ \\
Breadth $(\mathrm{B})$ & $14.00 \mathrm{~m}$ \\
Height $(\mathrm{H})$ & $3.80 \mathrm{~m}$ \\
Draught $(\mathrm{T})$ & $2.70 \mathrm{~m}$ \\
Ship speed $\left(\mathrm{V}_{\mathrm{S}}\right)$ & $11.0 \mathrm{knot}$ \\
Lateral projected windage area $\left(\mathrm{A}_{\mathrm{L}}\right)$ & $355.35 \mathrm{~m}^{2}$ \\
Transverse projected windage area $\left(\mathrm{A}_{\mathrm{F}}\right)$ & $156.07 \mathrm{~m}^{2}$ \\
Lateral projected area of superstructure $\left(\mathrm{A}_{\mathrm{OD}}\right)$ & $45.44 \mathrm{~m}^{2}$ \\
Center of windage area from midship $(\mathrm{C})$ & $-0.471 \mathrm{~m}$ \\
Vertical center of $\mathrm{A}_{\mathrm{L}}\left(\mathrm{H}_{\mathrm{C}}\right)$ & $3.598 \mathrm{~m}$ \\
Vertical center of $\mathrm{A}_{\mathrm{OD}}\left(\mathrm{H}_{\mathrm{L}}\right)$ & $9.948 \mathrm{~m}$ \\
Height of transverse projected area $\left(\mathrm{H}_{\mathrm{BR}}\right)$ & $11.148 \mathrm{~m}$ \\
\hline
\end{tabular}

Table 2 Propeller and rudder characteristics

\begin{tabular}{lr}
\hline \multicolumn{1}{c}{ Items } & \multicolumn{1}{c}{ Value } \\
\hline Number of propellers & 2 \\
Propeller blade $(\mathrm{Z})$ & 4 \\
Propeller diameter $\left(\mathrm{D}_{\mathrm{P}}\right)$ & $1.40 \mathrm{~m}$ \\
Propeller revolution $(\mathrm{n})$ & $9.55 \mathrm{rps}$ \\
Transverse position propeller $\left(\mathrm{y}_{\mathrm{P}}\right)$ & $\pm 2.55 \mathrm{~m}$ \\
Longitudinal position propeller $\left(\mathrm{x}_{\mathrm{P}}\right)$ & $24.38 \mathrm{~m}$ \\
Rudder area $\left(\mathrm{A}_{\mathrm{R}}\right)$ & $2.81 \mathrm{~m}^{2}$ \\
Transverse rudder position $\left(\mathrm{y}_{\mathrm{R}}\right)$ & $\pm 2.55 \mathrm{~m}$ \\
Longitudinal rudder position $\left(\mathrm{x}_{\mathrm{R}}\right)$ & $25.50 \mathrm{~m}$ \\
\hline
\end{tabular}

To identify the wind velocity up to which the rudder angle will not exceed its maximum, the simulated velocity was increased from $1 \mathrm{~m} / \mathrm{s}$ to $25 \mathrm{~m} / \mathrm{s}$. The wind direction relative to 
the ship varies according to the heading angle, which ranges from $0^{\circ} 0.0$ to $360^{\circ} 360.0$ degrees. The wind coefficients in the surge $(C A X)$, sway $(C A Y)$, and yaw $(C A N)$ directions of the local coordinate system are shown in Figure 2. Although the wind effect was symmetrically applied to the starboard and portside, the maneuvering motion naturally occurred in opposite directions, meaning that changes to the heading angle or ship motion would occur in different directions depending on the wind direction relative to the ship.

The thrust coefficient of the propeller described in the Table 2 was calculated for different advance coefficients using the following equation (Carlton, 2007):

$$
K_{T}=\sum_{n=1}^{39} C_{n}(J)^{S_{n}}(P / D)^{t_{n}}\left(A_{E} / A_{0}\right)^{u_{n}}(Z)^{v_{n}}
$$

Here, $C_{n}, S_{n}, t_{n}, u_{n}$, and $v_{n}$ are based on open water test data for B-series propeller (Carlton, 2007) with the assumption of a constant propeller revolution. To take into account the alteration of ship velocity during the numerical simulation, the thrust coefficient is represented as a function of the advance coefficient in a polynomial regression equation, as shown in Equation 7. This polynomial equation was developed based on the thrust coefficients obtained with Equation 6. The thrust coefficient $\left(K_{T}\right)$, torque coefficient $\left(K_{Q}\right)$, and efficiency $(\eta)$ of the propeller are presented in Figure 3.

$$
K_{T}(J)=0.3128-0.3406 J-0.1094 J^{2}
$$

where $J$ is the advance coefficient of the propeller.



Figure 2 Coefficients for wind forces and moments

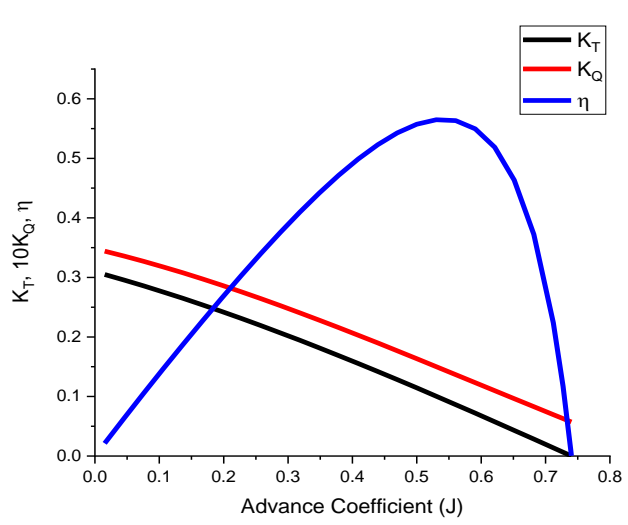

Figure 3 Thrust coefficient of the propeller

\section{Results and Discussion}

The steady state equilibrium of the ship is shown in Figure 4 for wind velocities $\left(U_{w}\right)$ of $10 \mathrm{~m} / \mathrm{s}, 15 \mathrm{~m} / \mathrm{s}, 20 \mathrm{~m} / \mathrm{s}$, and $25 \mathrm{~m} / \mathrm{s}$; the horizontal and vertical axes indicate the rudder angle and the heading angle, respectively. The rudder angle required to maintain the ship's direction increased as wind velocity increased, and the heading angle with the largest required rudder angle tended to decrease as wind velocity increased. This is because the wind force and moment coefficients shown in Figure 2 alternated with the wind direction relative to the ship. The required rudder angle exceeded the maximum available rudder angle $\left( \pm 35^{\circ} 35.0\right.$ degrees) under a wind velocity of $24 \mathrm{~m} / \mathrm{s}$ ( 4.24 of ship velocity) or greater. 


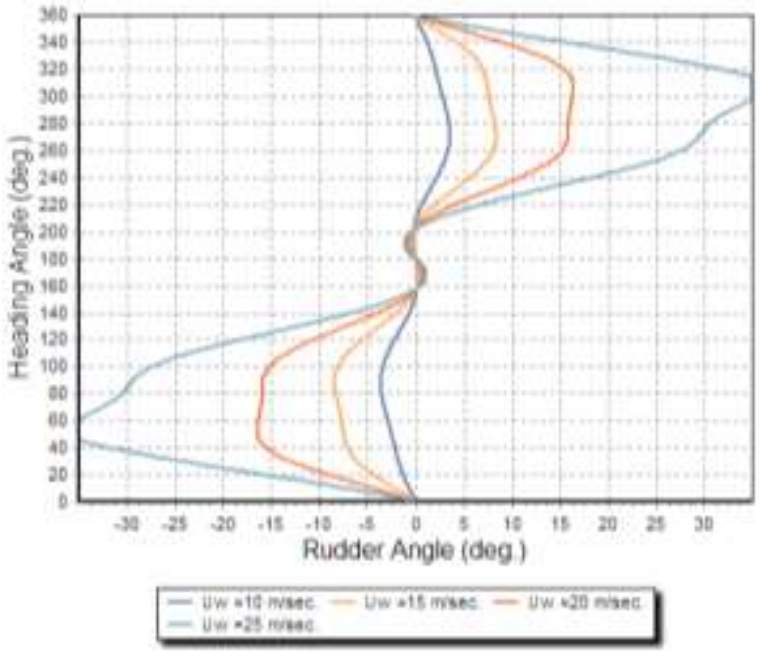

Figure 4 Steady state equilibrium points

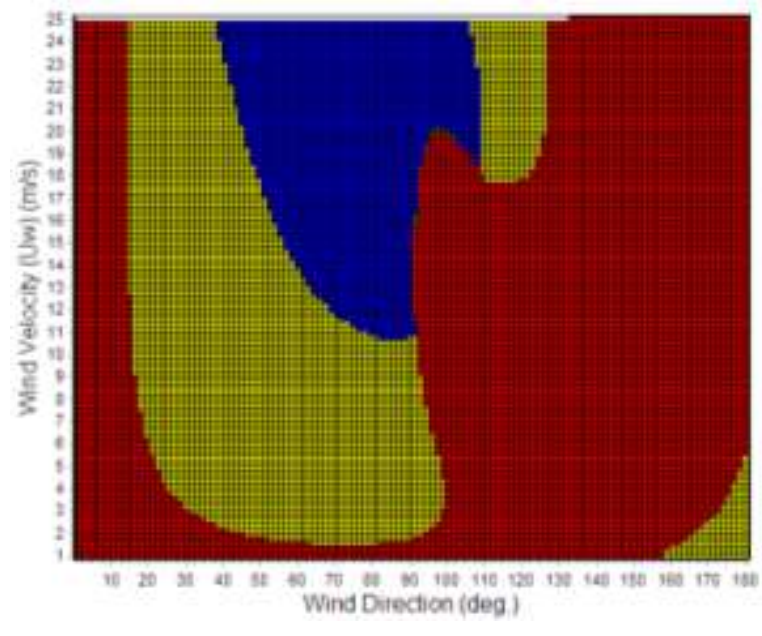

Figure 5 Stability of yaw motion

The equilibrium point exists at two heading angles for each rudder angle. In contrast, equilibrium may occur at four different heading angles for small rudder angles. This means that even when the rudder angle is constant, the heading angle may change from one equilibrium point to another depending on the yaw stability of each point. If a small disturbance is applied to the unstable equilibrium point, the yaw rate will gradually increase with time. As a result, the heading angle increases with time toward the stable equilibrium point. Figure 5 shows the stability characteristics of the yaw motion at steady state equilibrium for different wind velocities and directions. The red area indicates the equilibrium point with unstable yaw at which the eigenvalues are real and at least one eigenvalue is positive. The yellow area indicates unstable yaw motion with one (or pairs of) complex eigenvalue(s) with a positive real part; here, the yaw motion oscillates with increasing amplitude over time. As a result, the heading angle also oscillates with increasing amplitude over time toward a heading angle with a stable equilibrium. The blue area indicates the equilibrium point with stable yaw oscillation. Here, the eigenvalues are complex and all real parts are negative; the yaw oscillation decays, while the yaw rate and the heading angle become constant after a certain period of time.

The yaw motion was unstable for all wind directions at wind velocities smaller than 2 $\mathrm{m} / \mathrm{s}$ or 0.34 of ship velocity. This meant that the ship would perform a turning maneuver because all the equilibrium points within this range of wind velocity were unstable. Unstable yaw with oscillation was found for wind directions between $160^{\circ} 160.0$ and $180^{\circ} 180.0$ or in the following wind indicated by the yellow area. The range of heading angles decreased as wind velocity increased and disappeared in wind velocities larger than $5 \mathrm{~m} / \mathrm{s}$. Unstable yaw motion was also found in wind directions of $20^{\circ} 20.0$ degrees or smaller for all wind velocities. These cases of unstable yaw occurred due to the hysteresis of steady state equilibrium for heading angles between $150^{\circ} 150.0$ and $210^{\circ}$, as shown in Figure 4. A similar phenomenon was found by Yasukawa et al. (2012), even though the hysteresic characteristic does not typically exist for high wind velocities. Instead, this instability may have been due to an increase in the ship's forward speed induced by the wind, which caused the hydrodynamic forces and moments of the hull to dominate those induced by the rudder. Unstable equilibrium with yaw oscillation occurred for wind directions between $20^{\circ} 20.0$ and $100^{\circ} 100.0$ degrees with wind velocities larger than $2 \mathrm{~m} / \mathrm{s}$ and up to $11 \mathrm{~m} / \mathrm{s}$ or 1.95 of ship velocity. For wind velocities larger than $11 \mathrm{~m} / \mathrm{s}$, oscillating yaw motion was found up to a wind direction of $125^{\circ}$. This region of yaw 
oscillation is similar to that obtained by Yasukawa et al. (2012), albeit with a different range of wind velocities because of differences in ship and windage area dimensions. Liu et al. (2018) found that the effect of wind load on course-keeping failure depends on the geometric configuration of the windage area.

Stable yaw motion was found in wind velocities greater than $11 \mathrm{~m} / \mathrm{s}$ within a range of wind directions that increased as wind velocity increased. For example, the range of wind directions with stable yaw motion in a wind velocity of $24 \mathrm{~m} / \mathrm{s}$ was $40^{\circ} 40.0$ to $110^{\circ}$. The ship's heading angle could be maintained by the rudder because yaw motion decays and the heading angle becomes constant over time to infinity. An unstable equilibrium with yaw oscillation was also found in wind angles smaller than the lower boundary of the stable regions as well as wind angles larger than the upper boundary of the stable yaw motion. Here, the ship heading angle changed toward a heading angle with stable yaw oscillation, as indicated by the blue area in Figure 5. Stable limit cycle oscillation occurred at the lower boundary of the stable region in which the real part of the eigenvalue changed from positive to negative. The yaw motion and the heading angle oscillated at a certain amplitude with a constant rudder angle. Unstable limit cycle oscillation was found in the upper boundary of the stable region. Here, the amplitude of the yaw rate increased with time so that heading angle oscillation also increased with time until it reached the heading angle with stable conditions. For a wind velocity of $24 \mathrm{~m} / \mathrm{s}$, as table limit cycle region was found to range from $20^{\circ} 20.0$ to $35^{\circ} 35.0$ degrees in terms of wind direction, while unstable yaw motion occurred in wind directions between $105^{\circ} 105.0$ and $135^{\circ}$.

Figure 5 also shows that equilibrium points with unstable yaw motion occurred for heading angles smaller than that achieved at the maximum rudder angle. If the heading angle was larger than that achieved at the maximum rudder angle, the equilibrium points behaved as in stable yaw motion or unstable yaw motion with a stable limit cycle when the wind velocity was larger than $11 \mathrm{~m} / \mathrm{s}$. Similar results were found by Spyrou (1995) across four different ship types. The present results also showed that the range of the heading angle with oscillating yaw motion increased when the wind velocity was greater than $18 \mathrm{~m} / \mathrm{s}$ because the heading angle with the maximum rudder angle significantly decreased under these conditions. Therefore, the range of wind directions with limit cycles or stable yaw motion also increased as wind velocity increased for wind velocity larger than $18 \mathrm{~m} / \mathrm{s}$, as shown in Figure 5.

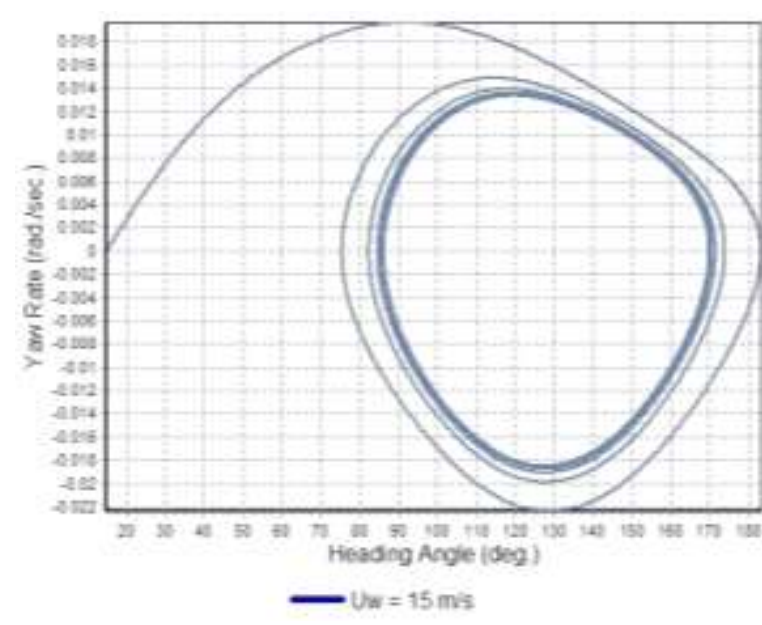

Figure 6 Transition of yaw motion from unstable equilibrium to stable limit cycles

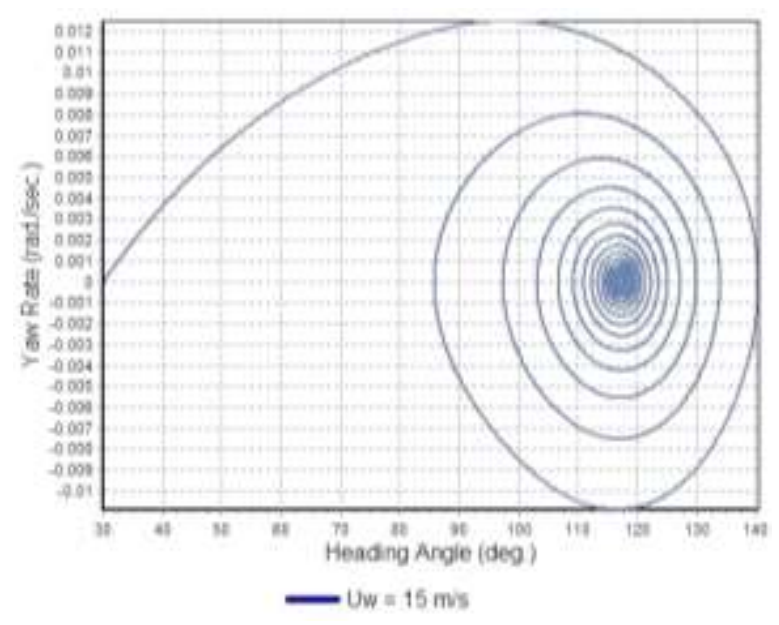

Figure 7 Transition of yaw motion from unstable equilibrium to a stable fixed point 


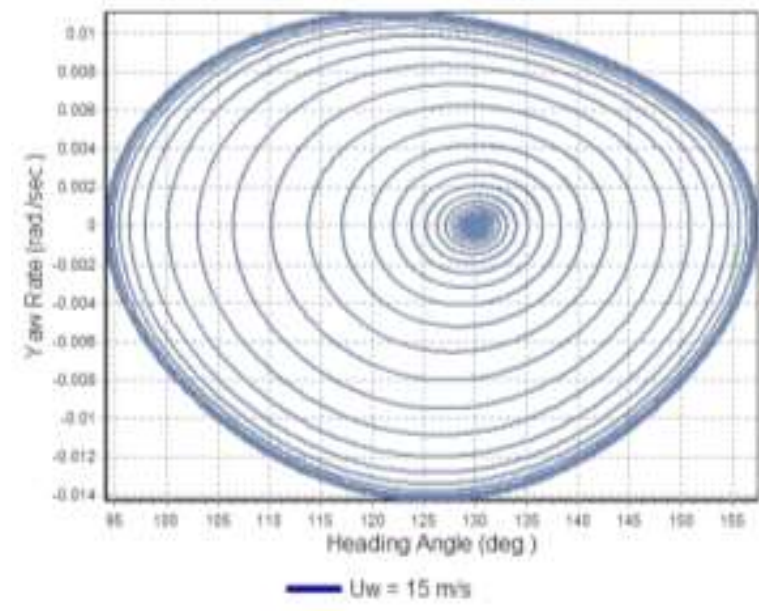

Figure 8 Limit cycle oscillation with a rudder angle of $3.76^{\circ} 3.76$ degrees

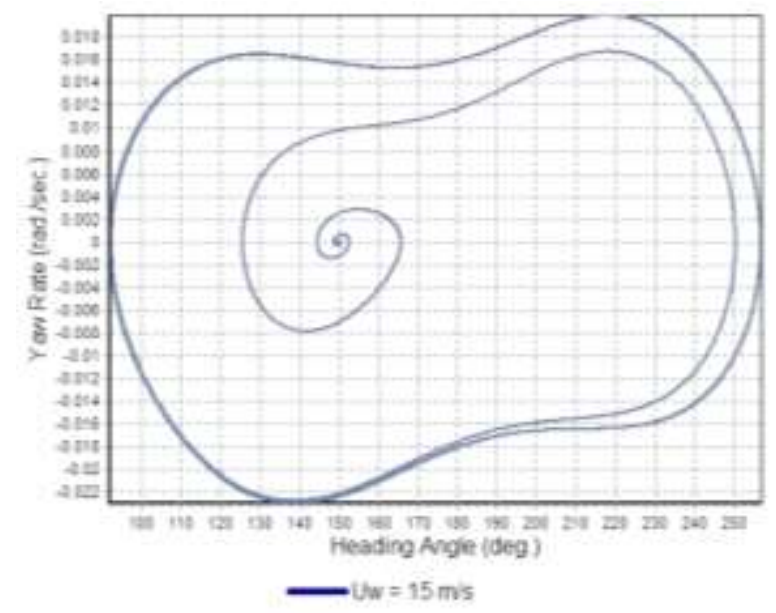

Figure 9 Limit cycle oscillation with a rudder angle of $0.55^{\circ} 0.55$ degrees

To identify the yaw motion characteristics at the equilibrium points with both stable and unstable yaw, particularly the existence of limit cycle oscillations, a numerical simulation was conducted by solving Equation 1 using the Runga-Kutta integration method with the respective equilibrium points as initial conditions. Figure 6 presents the results of this simulation with an initial condition of unstable equilibrium, a heading angle of $15^{\circ}$, a rudder angle of $3.25^{\circ} 3.25$ degrees toward the starboard, and a wind velocity $\left(U_{w}\right)$ of $15 \mathrm{~m} / \mathrm{s}$. The initial heading angle corresponds to a wind direction of $165^{\circ} 165.0$ degrees or a following wind and increases toward a stable limit cycle. Here, the heading angle oscillates between $85^{\circ} 85.0$ and $170^{\circ}$, and the yaw rate alternates between -0.018 and $0.014 \mathrm{rad} / \mathrm{s}$. The same phenomenon was observed for an initial heading angle of $30^{\circ}$, corresponding to a wind direction of $150^{\circ} 150.0$ degrees and a rudder angle of $6.04^{\circ} 6.04$ degrees toward the starboard, as shown in Figure 7. In this case, however, the final heading angle is stable so that the yaw rate decreases with time and ultimately vanishes to infinity. The center of the limit cycles in Figure 6 is unstable, as indicated by one eigenvalue with a positive real part. This instability can be further investigated using a mathematical simulation with an initial heading angle at the center of the limit cycles. As such, Figure 8 shows the evolution of yaw motion, starting from an initial heading angle of $130^{\circ} 130.0$ degrees at the cycle center and a rudder angle of $3.76^{\circ}$. Here, the heading angle increases due to the increase in yaw rate, approaches the limit cycle boundary, and oscillates there with a constant amplitude. Figure 9 presents another equilibrium point with limit cycle oscillation, in which the initial heading and rudder angles are $150^{\circ} 150.0$ and $0.55^{\circ}$ toward the starboard, respectively. This demonstrates that both the amplitude of the yaw rate and the heading angle in oscillating limit cycles tend to decrease when the rudder angle increases.

\section{Conclusions}

The yaw motion stability and course-keeping ability of an Indonesian ro-ro ferry were investigated under the action of steady wind through an analysis of the characteristic alteration of the eigenvalues obtained in a steady state maneuvering equilibrium. The results of the numerical simulation showed that a heading angle with the maximum rudder angle may significantly change in response to increases in wind velocity. The rudder angle required to maintain the ship's course was equivalent to the maximum possible rudder angle at a wind velocity of $24 \mathrm{~m} / \mathrm{s}$. The yaw motion at the equilibrium 
point was unstable when the heading angle was smaller than that obtained with the maximum rudder angle. Where heading angles are larger than that obtained with the maximum rudder angle, the equilibrium point may be stable or unstable with stable limit cycles, especially for wind velocities larger than the ship velocity. The effect of wind on the stability of yaw motion can be neglected if the wind velocity is smaller than 0.34 of ship velocity. Unstable equilibrium with stable limit cycles appeared when the wind velocity was larger than 0.34 of ship velocity, and stable yaw motion occurred when the wind velocity was larger than 1.95 of ship velocity. The limit cycles were stable for wind velocities between 0.34 and 1.95 of the ship velocity. Different characteristics of limit cycle oscillation were obtained for wind velocities larger than 1.95 of ship velocity; specifically, limit cycle oscillation was stable in headwinds and unstable in quartering winds.

\section{Acknowledgements}

This paper presents research supported by Hasanuddin University and the Directorate General of Higher Education of Indonesia under grant number 1764/UN4.20/PL.09/2016. The authors wish to express their gratitude to both institutions for their support. The authors also wish to express their sincere gratitude to PT Industri Kapal Indonesia (Persero) for its support in providing the ship data used in this paper.

\section{References}

Asri, S., Pallu, M.S., Thaha, M.A., Misliah, 2014. Intact Stability Criteria and Its Impact on Design of Indonesian Ro-Ro Ferries. International Journal of Engineering Research and Technology, Volume 3(3), pp. 1774-1779

Aung, M.Z., Umeda, N., 2018. Minimum Propulsion Power Prediction of a Ship under Adverse Weather Conditions with Dynamics of Diesel Engine and Turbocharger Taken into Account. In: Proceedings of the $7^{\text {th }}$ International Maritime Conference on Design for Safety. Kobe, Japan

Carlton, J.S., 2007. Marine Propellers and Propulsion, $2^{\text {nd }}$ Edition. Elsevier, Ltd. Jordan Hill, Oxford, United Kingdom

Fujiwara, T., Ueno, M., Ikeda, Y., 2006. Cruising Performance of a Large Passenger Ship in Heavy Sea. In: Proceedings of the $16^{\text {th }}$ International Polar and Polar Engineering Conference. San Francisco, USA

International Maritime Organization (IMO), 2002. Maritime Safety Committee on Ship Maneuverability of International Maritime Organization (IMO), MSC 76/23, Resolution MSC 137(36). IMO, London, United Kingdom

Kijima, K., Katsuno, T., Nakiri, Y., Furukawa, Y., 1990. On the Maneuvering Performance of a Ship with the Parameter of Loading Condition. Journal of Society of Naval Architects of Japan, Volume 168, pp. 141-148

Liu, H., Ma, N., Gu, X.C., 2018. Probabilistics Analysis of Container Ship Course Keeping Failure Under Environmental Loads in a Channel. In: Proceedings of the $7^{\text {th }}$ International Maritime Conference on Design for Safety. Kobe, Japan

Muhammad, A.H., Hasbullah, M., Djabbar, M.A., Handayani, 2015. Comparison Between Conventional and Azimuthing Podded Propulsion on Maneuvering of a Ferry Utilizing Matlab Simulink Program. International Journal of Technology, Volume 6(3), pp. 452461 
Paroka, D., Muhammad, A.H., Asri, S., 2015. Steady State Equilibrium of Ships Maneuvering under Combined Action of Wind and Wave. Jurnal of Teknologi (Science and Engineering), Volume 76(1), pp. 67-75

Paroka, D., Muhammad, A.H., Asri, S., 2017. Prediction of Ship Turning Maneuvering in Constant Wind and Regular Waves. International Journal of Technology, Volume 8(3), pp. 388-398

Shigunov, V., 2018. Maneuverability in Adverse Conditions: Rational Criteria and Standards. Journal of Marine Science and Technology, Volume 23, pp. 958-976

Somieski, G., 2001. An Eigenvalue Method for Calculation of Stability and Limit Cycles in Nonlinear Systems. Journal of Nonlinear Dynamics, Volume 26, pp. 3-22

Spyrou, K.J., 1995. Yaw Stability of Ships in Steady Wind. Journal of Ship Research, Volume42(1), pp. 21-30

Spyrou, K.J., Chatzis, A., Tigkas, I., Eleftheriadis, G., 2005. Limits of Controllability of a RoPax in Wind. In: The $16^{\text {th }}$ International Conference on Hydrodynamics in Ship Design. Gdansk-Ostroda, Poland

Spyrou, K.J., Tigkas, I., Chatzis, A., 2007. Dynamics of a Ship Steering in Wind Revisited. Journal of Ship Research, Volume 51(2), pp. 160-173

Sunaryo, Priadi, A.A., Tjahjono, T., 2015. Implementation of Traffic Separation Scheme for Preventing Accidents on the Sunda Strait. International Journal of Technology, Volume 6(6), pp. 990-997

Yasukawa, H., Hirano, T., Nakayama, Y., Koh, K.K., 2012. Course Stability and Yaw Motion of a Ship in Steady Wind. Journal of Marine Science and Technology, Volume 17, pp. 291-304

Yoshimura, Y., Matsumoto, Y., 2012. Hydrodynamic Data Base and Maneuvering Prediction Method with Medium-High Speed Merchant Ships and Fishing Vessels. In: Proceedings of the International Conference on Marine Simulation and Ship Maneuverability. Singapore, Singapore 